\title{
Comparative Evaluation of Mesio-Distal width of Six Anterior Maxillary Teeth in Jammu Region.
}

\author{
Dr.Reecha Gupta ${ }^{1}$.Dr. Mohit Gupta ${ }^{2}$. Dr. Bhavna Gupta ${ }^{3}$ \\ Associate Professor, Department Of Prosthodontics \& DM, I.G.G.D.C, Jammu. \\ Consultant Orthodontist Private Practioner, Jammu. \\ Post Graduate Student, Swami Devi Dyal Dental College And Hospital,Barnala, Haryana.
}

\begin{abstract}
Aesthetics is one of the key factorials in dental sciences which is not based on any fixed rules. SPA concept was prescribed to aid clinicians in selection of teeth according to age, sex and personality of the patient.

Materials \& method: 200 students comprising of 100 males and 100 females were taken in the study. Alginate impressions were made of maxillary arches and casts were poured in Type III dental stone. Measurements were done using Vernier caliper for individual tooth. A line following the maximum contours of teeth was drawn perpendicular to the long axis of teeth and measurements were carried out for all 100 maxillary casts. Thread was also used to measure Mesiodistal width of three teeth on both right and left sides and entire mesiodistal width of 6 teeth. Data was collected and statistically analyzed.

Result: The mean mesio distal width of all six anterior teeth was found to be $47.1 \mathrm{~mm}$ in males and $46.1 \mathrm{~mm}$ in females. In males, the mean mesio distal width of three anterior teeth on right and left side was found to be 23.8 $\mathrm{mm}$ and $23.3 \mathrm{~mm}$ respectively. In females, The mean mesio distal width of three anterior teeth on right and left side was found to be $23.4 \mathrm{~mm}$ and $22.7 \mathrm{~mm}$ respectively The mean difference between central incisors, lateral Incisors and canines on right and left side was found to be $0.1 \mathrm{~mm}, 0.2 \mathrm{~mm}$ and $0.2 \mathrm{~mm}$ in males and $0.2 \mathrm{~mm}, 0.3$ $\mathrm{mm}$ and $0.2 \mathrm{~mm}$ in females respectively.

Conclusion: The mesio-distal width of anterior maxillary teeth was found more in males than females. Both males and females have more mesio-distal width on right side than left side in population of Jammu.
\end{abstract}

Keywords: Impression, Casts, Mesio-distal, Vernier.

\section{Introduction}

Dentogenesis concept or SPA concept was prescribed by Frush and Fisher ${ }^{1}$ to aid clinicians in selection of teeth according to age, sex and personality of the patient. Besides the function of chewing food, Teeth provide an outlook to the person and reflect his attitude towards life. The inclusion of aesthetics in dentistry is never guided by any strict thumb rule but following certain established guidelines by the dentist, reproducing capacity of the technician and cooperation of the patient helps in achievement of desired esthetics ${ }^{2}$. Several proportions like Golden proportion ${ }^{3}$ and red proportions are prescribed and are followed widely but they can't be taken as standard in every case. Several edentulous patients require replacement of missing teeth which can't be fulfilled by a single size, shape and shade of artificial teeth. The aim of the study is to evaluate the mesiodistal width of 6 maxillary anterior teeth in Jammu region to help us in fabricating more "life-like" prosthesis. Null hypothesis states no difference in teeth selection with gender as criterion.

\section{Materials \& method}

The study was conducted on 200 students in Indira Gandhi Govt. dental College, Jammu comprising of 100 males and 100 females. Exclusion criteria were followed and alginate impressions were made of maxillary arches using manufacturer's recommendations (Tropicalgin). Impressions were poured in Type III dental stone. Casts were recovered and measurements were done using Vernier caliper for individual tooth. A line following the maximum contours of teeth was drawn perpendicular to the long axis of teeth and measurements were carried out for all 100 maxillary casts. Thread was also used to measure Mesiodistal width of three teeth on both right and left sides and entire mesiodistal width of 6 teeth. Data was collected and statistically analyzed.

\section{Results}

The combined mesio-distal width of 6 anterior teeth, mesiodistal width of 3 teeth on right and left side and mesio-distal width of individual teeth were measured and mean values were calculated. The mean mesio distal width of all six anterior teeth was found to be $47.1 \mathrm{~mm}$ in males and $46.1 \mathrm{~mm}$ in females. In males, the mean mesio distal width of three anterior teeth on right and left side was found to be $23.8 \mathrm{~mm}$ and $23.3 \mathrm{~mm}$ respectively. In females, The mean mesio distal width of three anterior teeth on right and left side was found to be $23.4 \mathrm{~mm}$ and $22.7 \mathrm{~mm}$ respectively The mean difference between central incisors, lateral Incisors and canines 
on right and left side was found to be $0.1 \mathrm{~mm}, 0.2 \mathrm{~mm}$ and $0.2 \mathrm{~mm}$ in males and $0.2 \mathrm{~mm}, 0.3 \mathrm{~mm}$ and $0.2 \mathrm{~mm}$ in females respectively.

\section{Discussion}

Entire human body is there in proportions and teeth are no different from this phenomenon. Out of all the proportions, width is considered the most important. ${ }^{4}$ Various standard textbooks ${ }^{5,6}$ have stated the mean width of teeth and described anatomical variations in respect to left and right side but none of the textbooks have demarcated the size on the basis of gender. Even manufacturers prepare the mold size according to recommendations of these textbooks keeping little regard to the masculine or feminine character. The null hypothesis that no difference exists between males and females of Jammu region on the basis of mesio distal width of teeth stands rejected as a positive interaction exists between the two groups. Textbooks ${ }^{5,6}$ recommend the size of $8.5 \mathrm{~mm}$ and $8.6 \mathrm{~mm}$ for central incisor, $6.5 \mathrm{~mm}$ and $6.6 \mathrm{~mm}$ for lateral Incisor and 7.5 and $7.6 \mathrm{~mm}$ for maxillary canine. In Group A (Males), 11 was found to have mean width of $8.6 \mathrm{~mm}$ and that of 21 was $8.5 \mathrm{~mm}$, 12 was having mean width of $7.2 \mathrm{~mm}$ and $6.9 \mathrm{~mm}$ for 22 and mean width of 13 was $8.1 \mathrm{~mm}$ and $7.9 \mathrm{~mm}$ for 23 , where as in Group B (Females), 11 was having mean width of $8.4 \mathrm{~mm}$ and that of 21 was $8.2 \mathrm{~mm}$. The mean width of 12 and 22 was $7.0 \mathrm{~mm}$ and $6.7 \mathrm{~mm}$ respectively and mean width of 13 and 23 was $8.0 \mathrm{~mm}$ and $7.8 \mathrm{~mm}$. This demonstrates the difference in mesiodistal width from that provided in books. Similar studies are carried by authors ${ }^{7,8}$ on Causician, North Indian populations and found different from the text book readings. Also, this study signifies and further strengthens the dynesthetic interpretation of the dentogenic concept ${ }^{1}$ that males have broader and bigger teeth than females.

An interesting point of interest was that right central incisor was found to be bigger than left one by 0.1 $\mathrm{mm}$ in males and $0.2 \mathrm{~mm}$ in females. Gam ${ }^{9}$ et al confirmed the result that means values of teeth on either side of midline are within the range of $0.3 \mathrm{~mm}$. Wazzara ${ }^{10}$ et al stated that difference of $0.1 \mathrm{~mm}$ between the two central Incisors to be normal which is less than the readings observed in the present study. The present study also demonstrates the difference in mean mesio-distal width of six anterior teeth. Increased width was found in males than females by $0.1 \mathrm{~mm}$. This study is in accordance to the study by the Lenmart and Nils ${ }^{11}$ which suggest boys to have greater mesiodistal width than girls. $\mathrm{Gam}^{9}$ et al also confirms the results of present study and states that tooth crown size is mediated by X or Y chromosome. Females also have greater variability in teeth morphology as crown size is mediated by $\mathrm{X}$ chromosome in diploid females as compared to haploid males. In both the groups, it was calculated that right side was found to have more mesio-distal width than left one. This suggests that teeth on both sides are never mirror images and should be taken in consideration while fabricating prosthesis with artificial teeth. Pamecha $\mathrm{S}$ and Dayakara $\mathrm{H}^{12}$ conducted similar study and found right and left sides to be never exactly the same. Further studies are directed to find out the correlation of maxillary and mandibular teeth and to study the coincidence of facial midline and dental midline. Clinical implications suggest manufacturers to take in consideration various factors which can change the tooth morphology and size.

\section{Conclusion}

The mesio-distal width of anterior maxillary teeth was found more in males than females. Both males and females have more mesio-distal width on right side than left side in population of Jammu.

\section{References}

[1]. Bolender Z. Prosthodontic treatment for edentulous patients. 2004; 12th edn. Mosby, St. Louis.

[2]. Kausal S, Patnaik VVG, Agnihotri G (2003) Mandibular canines in sex determination. J Anat Soc India 52:119-124.

[3]. Fuss Z, Tsesis I, Lin S. Root resorption - Diagnosis, classification and treatment choices based on stimulation factors. Dent Traumatol 2003;19:175-82.

[4]. Krajicek DD .Guides for natural facial appearance as related to completed denture construction. J Prosthet Dent 1969;21:654-662.

[5]. Ash MM, Stanley JN. Wheeler's dental anatomy, physiology and occlusion, 2003;

[6]. Jullian WB, Rickne CS. Dental anatomy: its relevance to dentistry, 2003; 5th edn. 8th edn. Saunders, Elsevier. Philadelphia.

[7]. Richardson ER, Malhotra SK. Mesiodistal crown dimension of the permanent dentition of American Negroes. Am J Orthod 1975;68:157-164.

[8]. McArthur DR. Determination of approximate size of maxillary anterior denture teeth when mandibular anterior teeth are present. Part III: Relationship of maxillary to mandibular central incisor width. J Prosthet Dent 1985; 53:541-542.

[9]. Garn SM, Lewis BL, Walenga AJ. Maximum-confidence values for the human mesiodistal crown dimension of human teeth. Arch Oral Biol 1968;13:841-844.

[10]. Wazzan KA, Haidan A, Madi E, Mufarj A. The relationship between facial references and mesiodistal width of maxillary anterior teeth among Saudi Patients. Am Dent Jour 1995;20:39-45.

[11]. Lennart L, Nils M. Mesiodistal tooth size in deciduous and permanent dentitions. Euro J Orthod 1982; 4:113-122.

[12]. Pamecha S and Dayakara HR. Comparative Measurement of Mesiodistal Width of Six Anterior Maxillary and Mandibular Teeth in Rajasthan Population. J Indian Prosthodont Soc 2012; 12:81-86.

Conflict of Interest: Nil. 
Table 1 \& 2 .

Table 1: Inclusion Criteria.

\begin{tabular}{|c|l|}
\hline 1. & No Crowding. \\
\hline 2. & Absence of Missing Teeth. \\
\hline 3. & Absence of Medical history. \\
\hline 4. & Absence of Supernumery teeth. \\
\hline 5. & Absence of Maxillofacial defects. \\
\hline 6. & Absence of Macrodontia or Microdontia or any other abnormalities. \\
\hline
\end{tabular}

Table 2: Mean values of mesio distall width.

\begin{tabular}{|c|c|l|l|c|c|c|}
\hline Tooth Number & Males: & & & Females: & & \\
\hline 11 & 8.6. & 23.8 rt side & & 8.4 & $\begin{array}{c}23.4 \text { rt } \\
\text { side }\end{array}$ & \\
\hline 12 & 7.2 & & & 7.0 & & \\
\hline 13 & 8.1 & & $\begin{array}{c}47.1 \\
\text { total }\end{array}$ & 8.0 & & 46.1 total \\
\hline 21 & 8.5 & 23.3 left side & & 8.2 & $\begin{array}{c}22.7 \text { left } \\
\text { side }\end{array}$ & \\
\hline 22 & 6.9 & & & 6.7 & & \\
\hline 23 & $23---7.9$ & & & 7.8 & & \\
\hline
\end{tabular}

Figure 1: Measurement of Individual tooth by vernier caliper.

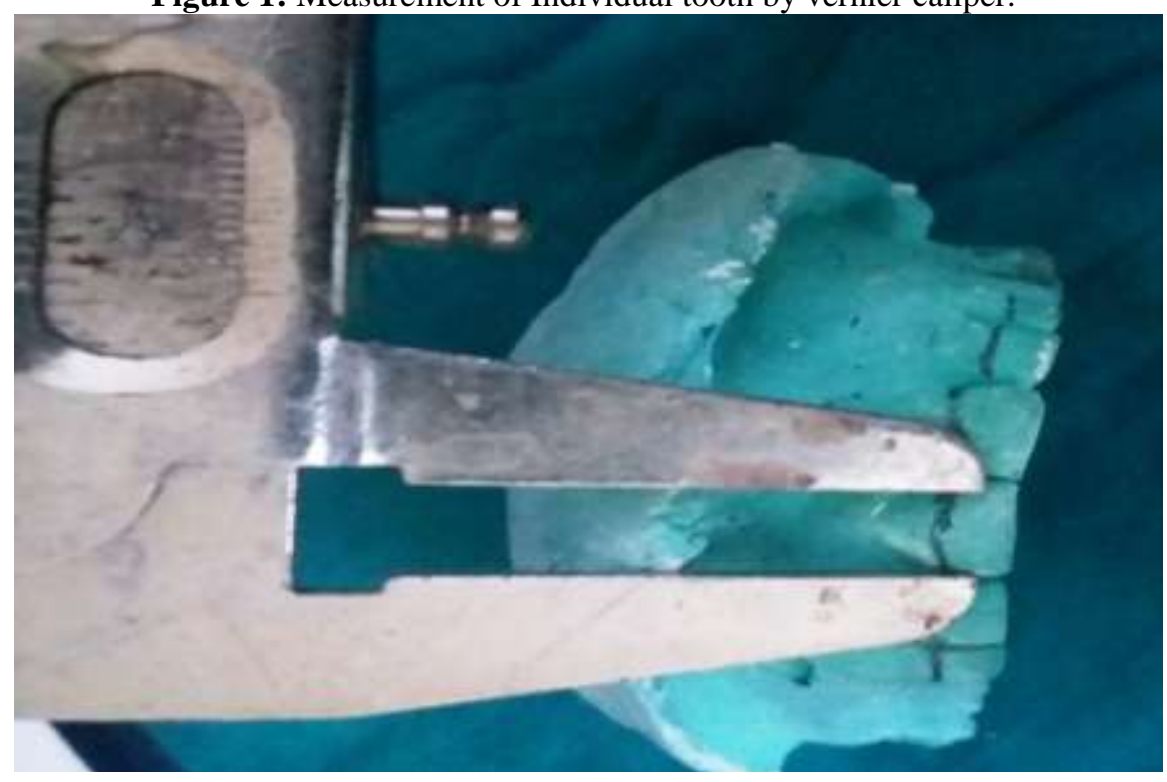

